\title{
QUANTIFICATION OF MICRODAMAGE PHENOMENA DURING TENSILE STRAINING OF HIGH VOLUME FRACTION PARTICLE REINFORCED ALUMINIUM
}

\author{
M. KOUZELI, L. WEBER, C. SAN MARCHI and A. MORTENSEN* \\ Laboratory for Mechanical Metallurgy, Swiss Federal Institute of Technology, 1015 Lausanne, Switzerland
}

(Received 31 August 2000; accepted 12 September 2000)

\begin{abstract}
Particle reinforced composites are produced by infiltrating ceramic particle beds with $99.99 \%$ Al. Resulting materials feature a relatively high volume fraction $(40-55$ vol. pct $)$ of homogeneously distributed reinforcement. The evolution of damage during tensile straining of these composites is monitored using two indirect methods; namely by tracking changes in density and in Young's modulus. Identification and quantification of the active damage mechanisms is conducted on polished sections of failed tensile specimens; particle fracture and void formation in the matrix are the predominant damage micromechanisms in these materials. The damage parameter derived from the change in density at a given strain is found to be one to two orders of magnitude smaller than the parameter based on changes in Young's modulus. A simple micromechanical analysis inspired by the observed damage micromechanisms is used to correlate the two indirect measurements of damage. The predictions of this analysis are in good agreement with experiment. (C) 2001 Acta Materialia Inc. Published by Elsevier Science Ltd. All rights reserved.
\end{abstract}

Keywords: Composites; Theory \& modelling: defects; Theory \& modelling: structural behaviour

\section{INTRODUCTION}

Damage evolution in metal matrix composites (MMCs) has received increasing attention in recent years due to the important link that has been established between their low ductility and the cumulative internal degradation of these materials during straining. Experimental studies have determined that the predominant damage micromechanisms leading to this degradation are: (i) reinforcement fracture, (ii) void nucleation and growth in the matrix and (iii) debonding along the matrix/reinforcement interface [1-12]. With respect to the influence of basic microstructural parameters on the rate of damage accumulation, it has been shown that increasing reinforcement size, angularity, aspect ratio, volume fraction, inhomogeneity in spatial distribution, interface degradation and matrix strength increases the level of damage in particle reinforced MMCs [13-25].

Numerous theoretical studies have been undertaken to elucidate the effects of basic microstructural parameters on the accumulation of damage and the link that exists between damage and the composite mech-

\footnotetext{
* To whom all correspondence should be addressed. Fax: +41-216-934-664.

E-mail address: Andreas.Mortensen@epfl.ch Mortensen)
}

anical response. While some of the work has focused on the introduction of damage in finite element models [26-31], others have treated the problem using principles of continuum damage mechanics [32-34]. In this second framework, damage is incorporated to global constitutive equations by introducing a damage parameter $D$ that accounts for the gradual decrease in flow stress with accumulating damage in the material. In its simplest form, $D$ is a scalar parameter and is used to define an effective stress, $\sigma_{\text {eff }}$, linked to the applied stress $\sigma$ by [35]

$$
\sigma_{\text {eff }}=\frac{\sigma}{1-D}
$$

Usually $D$ is chosen such that the actual mechanical behaviour of the material can be described by replacement of the apparent stress, $\sigma$, by the effective stress, $\sigma_{\text {eff }}$, in the constitutive laws corresponding to the material in the undamaged state. In general, $D$ is not a constant but an increasing function of stress or strain and its evolution provides insight to the mechanisms that eventually lead to failure. When the undamaged material response is not known a priori, and one still considers the actual mechanical response of the material as a combined result of intrinsic constitutive behaviour and damage accumulation, iso- 
lation of the effects of damage can be achieved solely through independent monitoring of damage evolution.

There exist numerous experimental techniques that can provide such measures of $D$ and these have broadly been classified into two categories: direct and indirect [36]. Both types of measures have been employed to determine the evolution of damage in particle reinforced MMCs [24, 37-43]. Direct methods rely on the microscopic determination of the nature and extent of active damage mechanisms. Although these methods yield information that is indispensable for the physical understanding of the damage process, they are mostly qualitative (unless statistically significant quantitative metallography can be achieved, e.g. [6, 44, 45]). Indirect methods, on the other hand, study the evolution of a physical property of the deforming material which is influenced by the accumulation of damage. Among others, monitoring of the changes in Young's modulus and in density have been used to derive the damage parameters $D_{E}$ and $D_{\rho}$, respectively, defined as:

$$
D_{E}=1-E / E_{0}
$$

and

$$
D_{\rho}=1-\rho / \rho_{0}
$$

where $E$ and $\rho$ are the Young's modulus and density as a function of strain, and $E_{0}$ and $\rho_{0}$ are the respective initial values. Each of these parameters has its advantages and drawbacks as damage descriptors in a continuum mechanics framework. While the evolution of the effective stress in a material seems intuitively better described by $D_{E}$, since it is a parameter directly derived from stress measurements, $D_{\rho}$ is the appropriate damage parameter if one wants to determine the point of tensile instability in materials which accumulate damage by void growth during tensile deformation [34].

It would be of interest to establish a link between $D_{E}$ and $D_{\rho}$; however, such a link is not straightforward, and strongly depends on the specific material and the operative damage mechanisms. For example, in a homogeneous body containing pores elongated parallel to the tensile axis, $D_{E}$ and $D_{\rho}$ have been shown to be roughly equal [46]. For spherical pores in a homogenous elastic body, $D_{E}$ is about thrice $D_{\rho}$ [47], while a distribution of penny-shaped cracks in an otherwise homogeneous material results in values of $D_{E}$ orders of magnitudes larger than $D_{\rho}$ (since the latter is essentially zero). Furthermore, when the body under consideration is not homogeneous but composed of two or more phases as is the case for metal matrix composites, the correlation is further complicated, largely due to the fact that damage is generally unequally distributed in the respective phases.

In what follows we report on the nature and evol- ution of damage in infiltrated particle reinforced aluminium composites. We show that (i) damage accumulation is a strong function of both the type and the size of reinforcement and (ii) that the two indirect measures of damage accumulation, $D_{E}$ and $D_{\rho}$, yield very different values for these composites. We then propose a micromechanical analysis to establish a link between the two damage parameters.

\section{EXPERIMENTAL PROCEDURES}

\subsection{Materials}

The composites were produced by infiltrating loose ceramic particle preforms, packed to their maximum tap density, with high purity aluminium (99.99\%). By varying the type and average size of the reinforcing ceramic phase, diverse composite microstructures were obtained. In specific, $\mathrm{Al}_{2} \mathrm{O}_{3}$ (Treibacher Schleifmittel, Germany) and $\mathrm{B}_{4} \mathrm{C}$ (Elektroschmelzwerk Kempten, Germany) powders of commercial grades between F-150 and F-1000 (FEPA-specified size distributions) were used to produce six composite castings; these materials will be referred to hereafter as $\mathrm{XY}$, where $\mathrm{X}$ is the average particle size in micrometers and $\mathrm{Y}$ is the initial of the ceramic reinforcement (for example $5 \mathrm{~A}$ designates aluminium reinforced with $\mathrm{Al}_{2} \mathrm{O}_{3}$ particles of $5 \mu \mathrm{m}$ average diameter, and 29B designates aluminium reinforced with $\mathrm{B}_{4} \mathrm{C}$ particles of $29 \mu \mathrm{m}$ average diameter).

The volume fraction of reinforcement was determined via high-precision density measurements based on an immersion technique. The flow stress of the composites was measured through tensile tests conducted according to ASTM standard B557M-84 on sub-sized dog-bone samples which were obtained by electro-discharge machining from the composite castings. Uniaxial loading of the specimens was conducted on a $10 \mathrm{kN}$ screw-driven universal testing machine. Longitudinal displacements were measured with a clip-on extensometer over a $10 \mathrm{~mm}$ gauge length and a nominal strain rate of $10^{-4} \mathrm{~s}^{-1}$ was used for all tests. The initial Young's modulus of the composites was measured upon repeated unloadings after a small increment in plastic deformation, less than $0.2 \%$ [49].

\subsection{Metallography}

Tensile specimens that were loaded to failure were sectioned parallel to the loading axis and mechanically polished using diamond-based procedures. Subsequently, a brief electrolytic polishing step was conducted (5 s at $50 \mathrm{~V}$ with Struers (Rodovre, Denmark) A2 electrolyte), which removes the smeared aluminium layer introduced by mechanical polishing and thus helps to reveal any voids within the matrix. Electrolytic polishing also allows for the distinction between superficial particle cracks caused by mechanical polishing and cracks running through particles that originate from particle failure during tensile straining. 
Quantification of the fraction of damaged particles was carried out for composites 58A, 58B, 29A, and 29B using SEM images (polishing difficulties rendered meaningful quantification impossible for composites $82 \mathrm{~B}$ and 5A). Measurements of the fraction of damaged particles were made in the gauge length of failed tensile specimens covering an area of at least 15 sampling windows $\left(300 \times 200 \mu^{2}\right.$ each on average). These measurements were subsequently averaged thus covering a total area between 500 and 1000 particles depending on the particle size. The region directly adjacent to the fracture surface $(3 \mathrm{~mm}$ from the fracture surface for all samples) was not considered so as to avoid the influence of localised deformation effects prior to failure. Homogeneity of deformation in the gauge length of the composites during tensile straining prior to the point of tensile instability was verified through photoelasticity measurements, using instrumentation purchased from Measurements Group Inc., Photoelastic Division (Raleigh, USA).

Determination of void volume fractions was also attempted, using the same SEM images acquired for the quantification of the fraction damaged particles and standard image analysis tools. Due to the low concentration of voids involved in these measurements, this quantification was found to be statistically insignificant for all composites but 29A and 29B.

\subsection{Damage monitoring}

2.3.1. Young's modulus evolution. Intermittent unload-reload cycles were repeated at strain increments of $0.2 \%$ to enable the monitoring of the Young's modulus with strain. At each predetermined strain increment several unload-reload cycles were performed (at least eight), so as to verify the reproducibility of the calculated moduli. During the first three to four cycles the apparent values for Young's modulus steadily increased, due to microplasticity in the soft aluminium matrix, and were disregarded. Further cycling results in stabilisation of the measured Young's modulus, in accordance to observations made by Prangnell et al. [50] and it is those stable values which are used in the determination of the damage parameter $D_{E}$ through equation (2). An average stress of 0.5 and a stress range of 0.4 of the maximum reached for each strain increment were used for these unload-reload cycles. The specific stress cycle was experimentally designed and aimed to minimise cyclic creep effects, also observed in the composites.

2.3.2. Density measurements. In a separate series of experiments, the evolution of void volume fraction is measured by high-precision density measurements after incremental plastic straining. A differential method for measuring small density changes based on Archimedes' principle is used [51]. The specimen is weighed with respect to a "dummy" sample of the same material both in air and the immersion fluid, before and after plastic straining. This method has the advantage that accurate measure- ment of temperature is not necessary since the changes in weight (in air and immersed) of the dummy sample are used to calibrate temperature variations.

A Sartorius MC 210P microbalance with a sensitivity of $\pm 10 \mu \mathrm{g}$ was used, with distilled water as the immersion fluid. Application of this technique ensures reliable density change measurements on the order of $\pm 0.005 \%$. Corrections are made for the unstrained volume beyond the shouldered ends of the tensile sample by assuming that all additional volume is generated in the gauge length of the sample. Density measurements on the shouldered ends of a failed tensile specimen confirmed that, indeed, no density change had occurred.

\section{RESULTS}

\subsection{Composite structure and properties}

Observation of polished sections of the as-cast composites in optical and electron microscopes revealed microstructures featuring homogeneously distributed reinforcements in a pore-free matrix (Fig. 1). In the non-reactive $\mathrm{Al}_{2} \mathrm{O}_{3}-\mathrm{Al}$ system no third phases were observed while small amounts of the reaction product, $\mathrm{AlB}_{2}$, were identified in the $\mathrm{B}_{4} \mathrm{C}-$ Al composites [48].

Basic mechanical properties of the composites are provided in Table 1. The quoted values of tensile properties are averages of at least three tensile tests. It should be noted that the $0.2 \%$ proof stress for these materials cannot be considered as a global yield point, since significant micro-yielding is apparent from the very beginning of tensile loading. The failure strain is measured at the tensile instability point according to Considere's criterion [34].

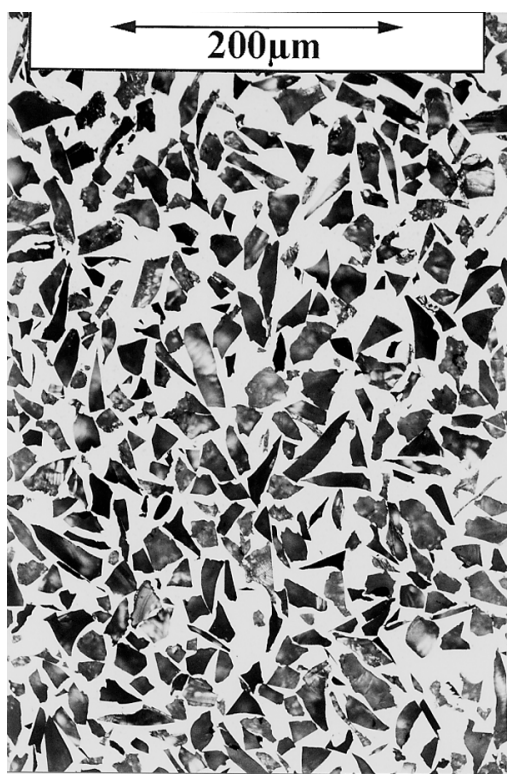

Fig. 1. As-cast composite 29A. 
Table 1. Composite properties

\begin{tabular}{|c|c|c|c|c|c|}
\hline $\begin{array}{l}\text { Composite } \\
\text { designation }\end{array}$ & Vol. pct reinforcement & $\begin{array}{l}\text { Young's modulus }( \pm 2) \text {, } \\
\mathrm{GPa}\end{array}$ & $\begin{array}{c}\text { Ultimate tensile } \\
\text { strength }( \pm 2), \mathrm{MPa}\end{array}$ & $\begin{array}{c}0.2 \% \text { Proof stress }( \pm 3) \\
\mathrm{MPa}\end{array}$ & $\begin{array}{c}\text { Strain at tensile } \\
\text { instability point }( \pm 0.5) \\
\%\end{array}$ \\
\hline $58 \mathrm{~A}$ & $43.4( \pm 0.5)$ & 134 & 97 & 66 & 2.6 \\
\hline $29 \mathrm{~A}$ & $44( \pm 0.5)$ & 138 & 118 & 82 & 2.3 \\
\hline $5 \mathrm{~A}$ & $40.4( \pm 0.5)$ & 131 & 249 & 158 & 2.7 \\
\hline $82 \mathrm{~B}$ & $52( \pm 2)$ & 166 & 111 & 86 & 1.4 \\
\hline $58 \mathrm{~B}$ & $54( \pm 2)$ & 169 & 132 & 91 & 2.6 \\
\hline 29B & $58( \pm 2)$ & 183 & 201 & 127 & 2.8 \\
\hline
\end{tabular}

\subsection{Damage}

Microscopic observations reveal significant differences in the micromechanisms of damage in the various composites. In $\mathrm{Al}_{2} \mathrm{O}_{3}$ reinforced composites, particle fracture is primarily responsible for damage accumulation with strain. Tensile specimens that were strained to $1 \%$, cut and polished, Fig. 2 demonstrates that particle cracking occurs even at very low strains. Particle fracture is dominated by particle-particle interactions within the composites. Cracks in particles often nucleate at (or near) particle-particle contact points and are induced predominantly by the high stress concentrations which occur at (or due to) these points. During subsequent plastic straining of the matrix, cracked-particle faces open up producing an
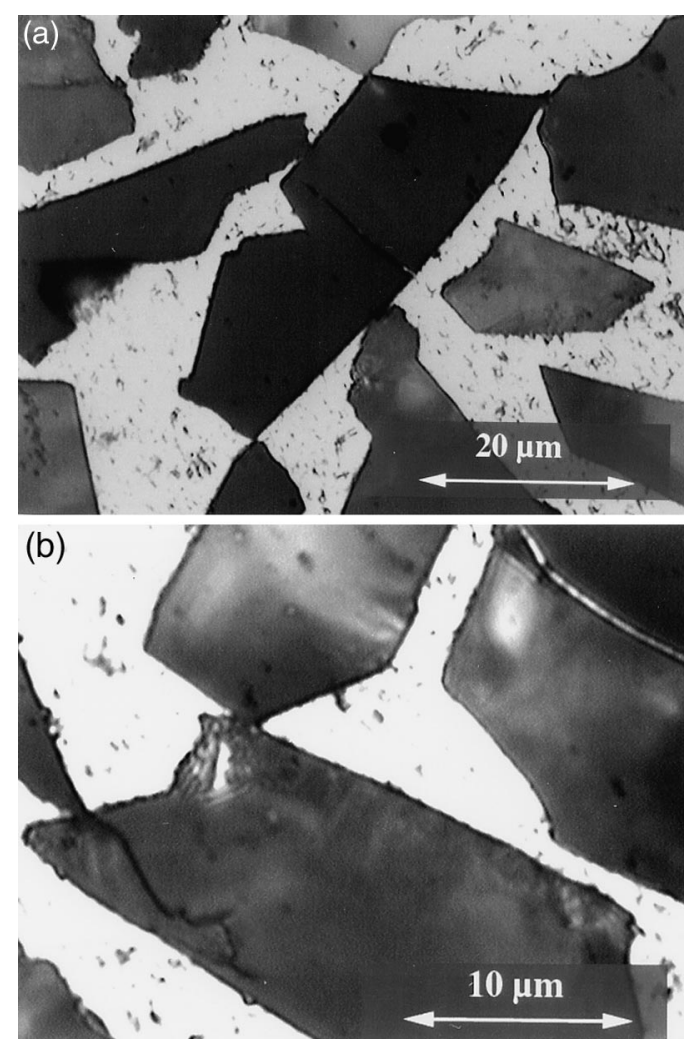

Fig. 2. (a) and (b) Optical micrographs of cracks in $\mathrm{Al}_{2} \mathrm{O}_{3}$ particles in composite 29A after tensile deformation of $1 \%$. Tensile axis is perpendicular to the scaling bar. increase in volume within the composites [Fig. 3(a)]. This mechanism was observed to be operative in all $\mathrm{Al}_{2} \mathrm{O}_{3}-\mathrm{Al}$ composites that were studied, and with a decreasing propensity as the average particle size decreases. Additionally, some matrix voids were observed to nucleate in composite $5 \mathrm{~A}$ at flat particle faces oriented perpendicular to the tensile stress axis.

In contrast to the $\mathrm{Al}_{2} \mathrm{O}_{3}-\mathrm{Al}$ composites, two concurrent damage mechanisms can be observed in the $\mathrm{B}_{4} \mathrm{C}-\mathrm{Al}$ composites: matrix voiding and particle cracking. Matrix voids in these composites develop in regions of high constraint between closely spaced particles [Fig. 3(b)]. These regions of high constraint occur more frequently in the microstructure of the $\mathrm{B}_{4} \mathrm{C}-\mathrm{Al}$ composites due to their relatively higher volume fractions in comparison to the $\mathrm{Al}_{2} \mathrm{O}_{3}-\mathrm{Al}$ composites. Particle cracking followed by crack-face opening with strain also occurs in the $\mathrm{B}_{4} \mathrm{C}-\mathrm{Al}$ composites, albeit with a lower frequency than in the $\mathrm{Al}_{2} \mathrm{O}_{3}-\mathrm{Al}$ composites. An increasing tendency for

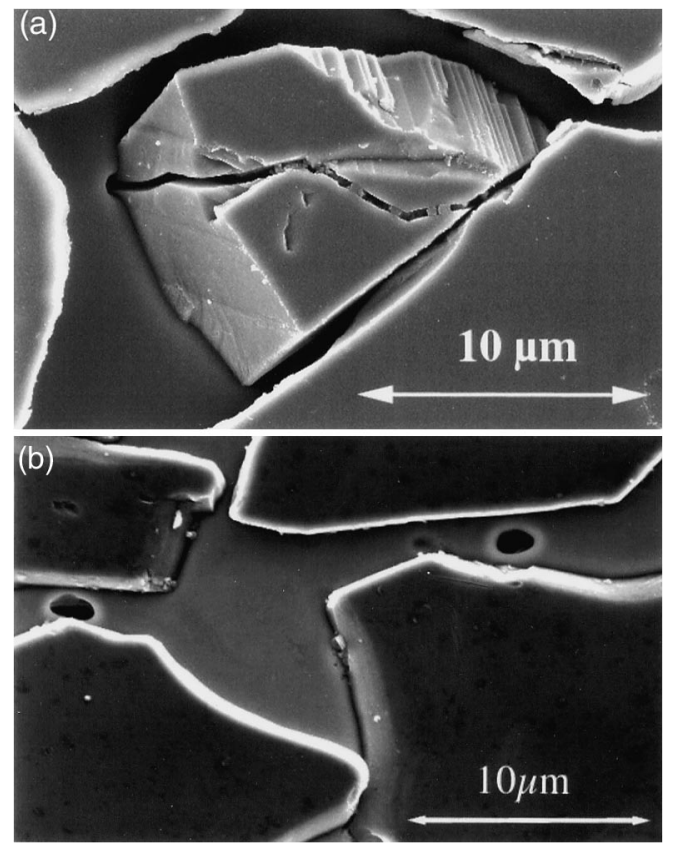

Fig. 3. Scanning electron micrographs of (a) particle cracking and subsequent crack face opening in composite 29A and (b) matrix voiding in composite $29 \mathrm{~B}$. Tensile axis is perpendicular to the scaling bar. 
Table 2. Quantification of damage phenomena

\begin{tabular}{lccc}
\hline $\begin{array}{c}\text { Composite designation } \\
\text { Fraction of broken particles } \\
\text { (at failure) }\end{array}$ & $\begin{array}{c}\text { Void Volume fraction (at } \\
\text { failure) }\end{array}$ & $\begin{array}{c}\text { Fraction of voids related to } \\
\text { broken particles (by } \\
\text { volume) }\end{array}$ & $\begin{array}{c}\text { Strain at failure, \% (for the } \\
\text { specific samples that were } \\
\text { examined) }\end{array}$ \\
\hline 58A & $0.28( \pm 0.05)$ & & 0.99 \\
29A & $0.31( \pm 0.04)$ & $0.0012( \pm 0.0006)$ & 4.6 \\
58B & $0.32( \pm 0.05)$ & & 3.3 \\
29B & $0.22( \pm 0.03)$ & $0.0018( \pm 0.0004)$ & 3.8 \\
\hline
\end{tabular}

particle fracture is also observed in these composites as the average particle diameter increases.

The results regarding the quantification of the damage micromechanisms are summarised in Table 2 and clearly show that, for a given strain, composites reinforced with large particles experience a higher rate of particle fracture. Furthermore, in the $\mathrm{B}_{4} \mathrm{C}-\mathrm{Al}$ composites the fraction of damaged particles is less than in the $\mathrm{Al}_{2} \mathrm{O}_{3}-\mathrm{Al}$ composites of equivalent reinforcement size. Average void volume fractions and an estimation (conducted by image analysis) of the relative contributions to void generation of the two dominant damage micromechanisms are also given in Table 2.

Measured values of $D_{E}$ for composite systems $\mathrm{Al}_{2} \mathrm{O}_{3}-\mathrm{Al}$ and $\mathrm{B}_{4} \mathrm{C}-\mathrm{Al}$ are given in Fig. 4(a and b) respectively, while corresponding values of $D_{\rho}$ are presented in Fig. 5(a and b). The microscopically determined values for $D_{\rho}$ from Table 2 are also indicated in Fig. 5(a and b). It should be noted that the
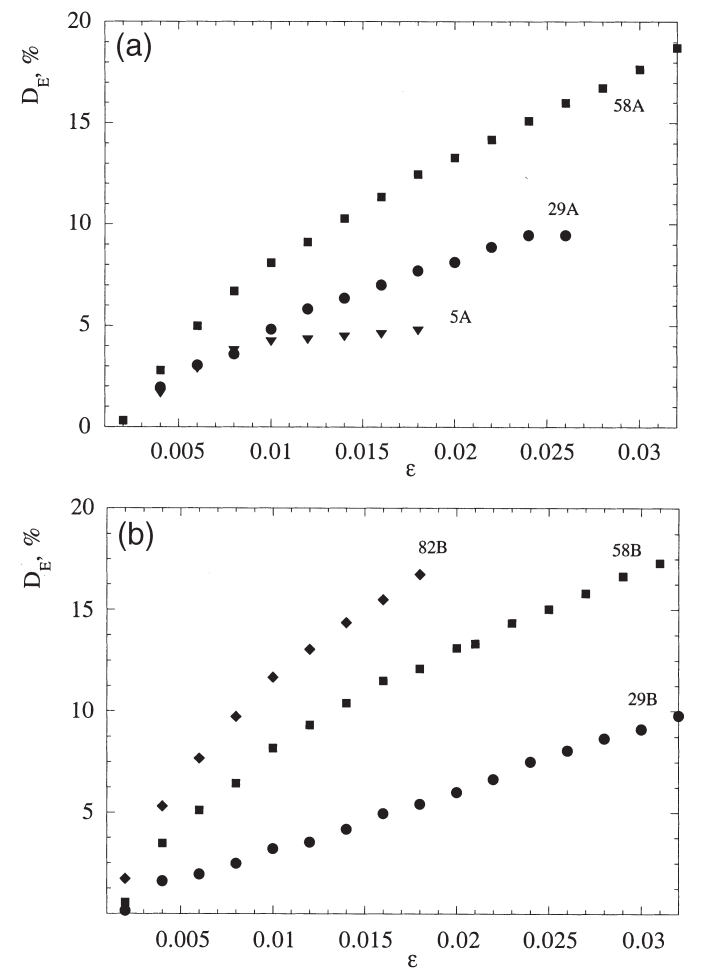

Fig. 4. Evolution of $D_{E}$ in (a) $\mathrm{Al}_{2} \mathrm{O}_{3}-\mathrm{Al}$ composites and (b) $\mathrm{B}_{4} \mathrm{C}-\mathrm{Al}$ composites.
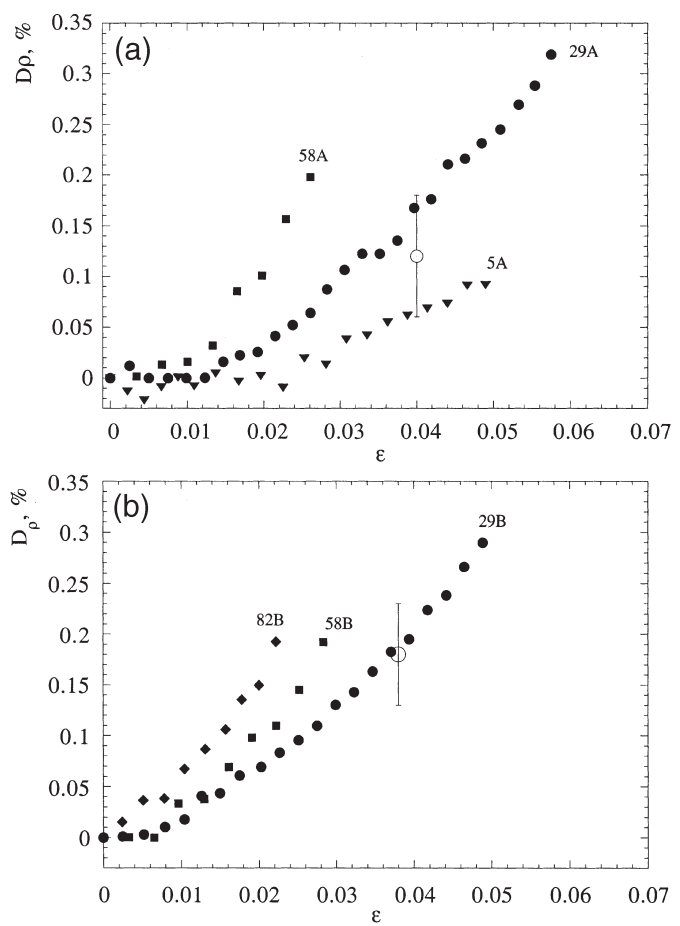

Fig. 5. Evolution of $D_{\rho}$ (closed symbols) in (a) $\mathrm{Al}_{2} \mathrm{O}_{3}-\mathrm{Al}$ composites and (b) $\mathrm{B}_{4} \mathrm{C}-\mathrm{Al}$ composites. The open symbols represent the void volume fraction as measured in materials $29 \mathrm{~A}$ and $\mathrm{B}$ respectively by image analysis.

total amount of plastic strain sustained during the experimental determination of $D_{\rho}$ is almost twice as high as in continuous tensile straining for small average reinforcements sizes in both composite systems. We attribute this to relaxation phenomena (the experiments for measuring density decrease can take between several days and a couple of weeks to complete for a given sample).

\section{DISCUSSION}

\subsection{Dependence of damage on the microstructure}

The rate of damage accumulation, measured both by $D_{E}$ and $D_{\rho}$, is largely dependent on particle size for both types of particles; this is in qualitative agreement with the microscopic observations and with previous studies of damage in particle reinforced composites (e.g. [6, 10, 11, 38, 45]). Furthermore, there is good quantitative agreement between direct and 
indirect measurements of void volume fractions (Fig. $5)$. The levels of damage, as measured by $D_{\rho}$, are slightly greater in $\mathrm{B}_{4} \mathrm{C}-\mathrm{Al}$ composites than in $\mathrm{Al}_{2} \mathrm{O}_{3}$ $\mathrm{Al}$ composites of equivalent reinforcement size. This difference increases as particle size decreases and can be attributed to the higher volume fractions in composites reinforced with smaller $\mathrm{B}_{4} \mathrm{C}$ particles, $\mathrm{cf}$. Table 1, resulting in a larger fraction of the matrix that is subjected to high triaxial stresses and, in turn, more matrix voiding.

The trends are reversed for damage as measured by $D_{E}$; for the same strain the $\mathrm{Al}_{2} \mathrm{O}_{3}-\mathrm{Al}$ composites suffer a greater loss of stiffness in comparison to the $\mathrm{B}_{4} \mathrm{C}-\mathrm{Al}$ composites of equivalent average particle size, and this difference also increases for composites reinforced with smaller particles. This reflects a relatively greater propensity for particle failure in the $\mathrm{Al}_{2} \mathrm{O}_{3}-\mathrm{Al}$ composites. The phenomena that dominate the accumulation of damage are thus manifest in the comparative evolution of the two parameters, $D_{E}$ being sensitive to reinforcement damage and $D_{\rho}$ capturing matrix void accumulation.

\subsection{Correlation of $D_{E}$ and $D_{\rho}$}

Comparison of the two indirect measures of damage reveals that they differ significantly: at given strain, $D_{E}$ is found to be one to two orders of magnitude greater than $D_{\rho}$ (Figs. 4 and 5). Several authors have correlated these two measures of damage for different materials [47, 52]; however, in those studies predicted and observed values of $D_{E}$ and $D_{\rho}$ differ by a factor around three. We develop a simple micromechanical analysis to relate and explain the large differences in the values of these two damage parameters for the present composites. Furthermore, since the void volume fraction generated by matrix voiding is small in comparison to particle cracking and subsequent crack-face opening for the particle sizes involved in the present study (Table 2), we base our analysis on the amount of void volume generated via the latter mechanism only.

Consider then a composite volume element that when strained in tension can undergo damage by reinforcement fracture. At a given composite strain $\varepsilon^{*}$ a particle, whose shape is described as a parallelepiped for simplicity, cracks in a random plane which intersects all four of its lateral faces. Assuming the particle no longer transfers any load in tension, further straining of the material forces open the cracked faces as the particle segments follow deformation of the surrounding material along the stress axis, cf. Fig. 6. Thus, the average strain increment along the length of the particle, $l$, parallel to the straining direction equals that of the composite as a whole. If the particle cross-section is $A$ then the volume generated by the crack-face separation is

$$
V_{\mathrm{void}}=A \cdot l \cdot\left(\varepsilon^{\mathrm{a}}-\varepsilon^{*}\right)
$$

where $\varepsilon^{\mathrm{a}}$ denotes the current composite strain. With

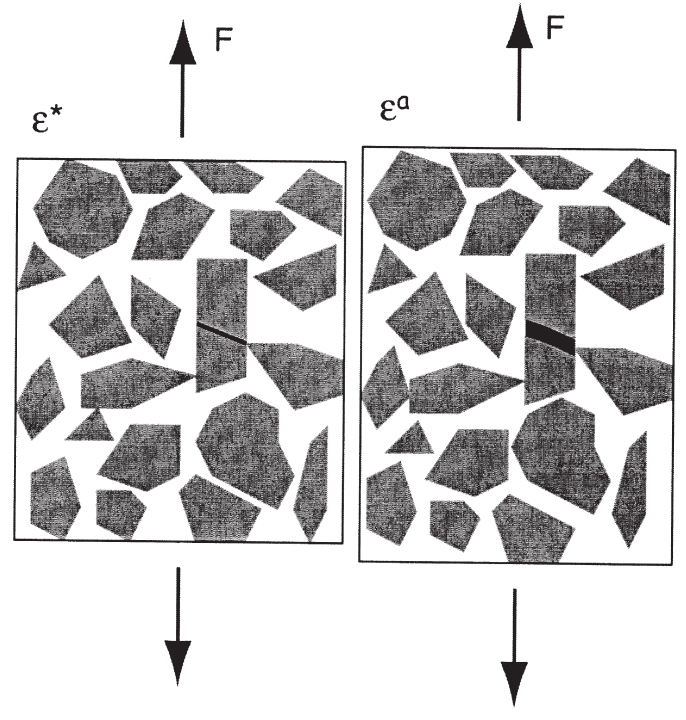

Fig. 6. Schematic depiction of void generation through straining of a cracked particle.

respect to the initial volume of the particle $\left(V_{0}=\right.$ $A l)$ this void volume can be expressed as

$$
\frac{V_{\text {void }}}{V_{0}}=\varepsilon^{\mathrm{a}}-\varepsilon^{*}
$$

and hence is independent of the dimensions of the particle. For cracks as defined above, the void volume is also independent of crack orientation so the analysis is not restricted to cracks perpendicular to the loading direction.

Assuming that the fraction of particles that are broken is a function of composite strain, $f_{\mathrm{b}}=h(\varepsilon)$, for a given strain $\varepsilon^{\mathrm{a}}$, the void volume fraction generated by the opening of cracked-particle faces, $v_{\text {void }}$, is

$$
v_{\text {void }}=\int_{0}^{\varepsilon^{\mathrm{a}}}\left(f_{\mathrm{p}}\right)_{0} \cdot \frac{\mathrm{d} h(\varepsilon)}{\mathrm{d} \varepsilon} \cdot\left(\varepsilon^{\mathrm{a}}-\varepsilon\right) \mathrm{d} \varepsilon
$$

where $\left(f_{\mathrm{p}}\right)_{0}$ is the initial concentration of reinforcement in the composite.

Since $v_{\text {void }} \approx 1-\rho / \rho_{0}$, combining equations (3) and (6) reduces the density-based damage parameter $D_{\rho}$ to a function of the evolution of the fraction of broken particles $h(\varepsilon)$, and the current composite strain $\varepsilon^{\mathrm{a}}$ which reads

$$
D_{\rho}=\int_{0}^{\varepsilon^{\mathrm{a}}}\left(f_{p}\right)_{0} \cdot \frac{\mathrm{d} h(\varepsilon)}{\mathrm{d} \varepsilon} \cdot\left(\varepsilon^{\mathrm{a}}-\varepsilon\right) \mathrm{d} \varepsilon
$$

To link $h(\varepsilon)$ with the damage parameter $D_{E}$ we follow the work of Mochida and co-workers [53], who 
have used a Mori-Tanaka back-stress analysis to correlate the loss of stiffness in a particle reinforced composite with the fraction of broken particles in its microstructure. In their model, the composite domain $(\Delta)$ comprises the particle domain $\left(\Omega_{\mathrm{p}}\right)$ of volume fraction $f_{\mathrm{p}}$, relating to the intact reinforcements which are modelled as spheres, a damage domain $\left(\Omega_{2}\right)$ of volume fraction $f_{2}$, relating to ellipsoidal voids of aspect ratio $t / c$ with which they replace the broken reinforcements, and the matrix domain which subsequently equals $\Delta-\Omega_{p}-\Omega_{2}$. After pursuing the same reasoning they develop in their study we obtain the following relationship linking the Young's modulus of the composite, $E_{\mathrm{c}}$, to the amount of broken particles in its microstructure

$$
\frac{E_{\mathrm{c}}}{E_{\mathrm{m}}}=\frac{1}{1+\eta_{\mathrm{p}}^{\mathrm{II}} \cdot f_{\mathrm{p}}+\eta_{2} \cdot f_{2}}
$$

where $E_{\mathrm{m}}$ is the Young's modulus of the matrix, and $\eta_{\mathrm{p}}^{\mathrm{II}}$ and $\eta_{2}$ are coefficients that depend on the elastic properties of the respective domains as well as the fraction of broken and intact particles (given explicitly in [53]). The volume fractions $f_{2}$ and $f_{\mathrm{p}}$ are related to the fraction of broken particles, $f_{\mathrm{b}}$, and the initial volume fraction of reinforcement $\left(f_{\mathrm{p}}\right)_{0}$, through the following relationships

$$
f_{2}=\bar{f}_{2} \cdot\left(\frac{t}{c}\right)
$$

where

$$
\bar{f}_{2}=f_{\mathrm{b}} \cdot\left(f_{\mathrm{p}}\right)_{0}
$$

and

$$
f_{\mathrm{p}}=\left(1-f_{\mathrm{b}}\right) \cdot\left(f_{\mathrm{p}}\right)_{0} \text {. }
$$

Equation (8) differs slightly from the explicit solution given by Mochida et al. [equation (31) of Reference 53] in that the aspect ratio of the crack (ellipsoidal void) does not appear in their solution. They replace the volume fraction, $f_{2}$, of the damage domain $\left(\Omega_{2}\right)$ with the volume fraction of the damaged particles, $\bar{f}_{2}$, thus effectively replacing the original particle with a spherical void (even though the calculation of the coefficient $\eta_{2}$ in Appendix B2 of Reference 53 is specific to aspect ratios much smaller than one $(c \gg t))$. The replacement of the original particle with a spherical void severely overestimates the reduction in stiffness due to particle fracture (as was pointed out by several authors $[54,55]$ ), thus equation (8) is considered to better describe the present composites in which the aspect ratio of particle cracks is observed to be closer to zero than to one [Fig. 3(a)].
The relationship linking the damage parameter $D_{E}$ and the fraction of damaged particles, $f_{\mathrm{b}}$, as calculated from equation (8) is then

$$
D_{E}=1-\frac{1+\eta_{\mathrm{p}}^{0} \cdot\left(f_{\mathrm{p}}\right)_{0}}{1+\eta_{\mathrm{p}}^{\mathrm{II}} \cdot\left(1-f_{\mathrm{b}}\right) \cdot\left(f_{\mathrm{p}}\right)_{0}+\eta_{2} \cdot f_{\mathrm{b}} \cdot\left(f_{\mathrm{p}}\right)_{0} \cdot(t / c)}
$$

where $\eta_{\mathrm{p}}^{0}$ is a coefficient given in the original reference [53]. The validity of the model is verified by comparison of the calculated curves of $h(\varepsilon)$ based on equation (12) to the experimental measurements of the fraction of broken particles (Table 2) correlated to their corresponding loss of modulus (Fig. 4). Reasonable agreement between the measured and calculated values is found (Fig. 7). The elastic constants used in the calculation are: $E_{\mathrm{Al}}=69 \mathrm{GPa}, E_{\mathrm{Al}_{2} \mathrm{O} 3}=$ $400 \mathrm{GPa}, E_{\mathrm{B}_{4} \mathrm{C}}=450 \mathrm{GPa}, v_{\mathrm{Al}}=0.345, v_{\mathrm{Al}_{2} \mathrm{O} 3}=$ 0.27 , and $v_{\mathrm{B}_{4} \mathrm{C}}=0.17[56,57]$; the aspect ratio of the ellipsoidal void was taken to be 0.001 (values for this aspect ratio up to $0.1-$ which represents an upper limit for the product of the aspect ratio of the reinforcements (between 1 and 3 ) and $\varepsilon^{\mathrm{a}}-\mathrm{do}$ not change the result by more than $1 \%$ ).

Approximating the experimental results of Fig. 4 as bilinear functions (with the exception of composite 29B which is linear) and combining with equation (12), the evolution of the fraction of broken particles, $h(\varepsilon)$, is determined. Substituting this function into equation (7) enables the calculation of the evolution of $D_{\rho}$ with strain. The results of these calculations are presented in Fig. 8 together with the experimentally determined data of Fig. 5; dashed lines correspond to strains for which calculated values of $D_{\rho}$ were based on extrapolated values of $D_{E}$.

The derived correlation between these two indirect measures of damage shows good overall agreement with data. The considerable difference between the two damage parameters is thus explained as being a direct consequence of the nature of damage and the elastoplastic character of the studied composites. In particular, the correlation between $D_{E}$ and $D_{\rho}$ is slightly better described for composites containing

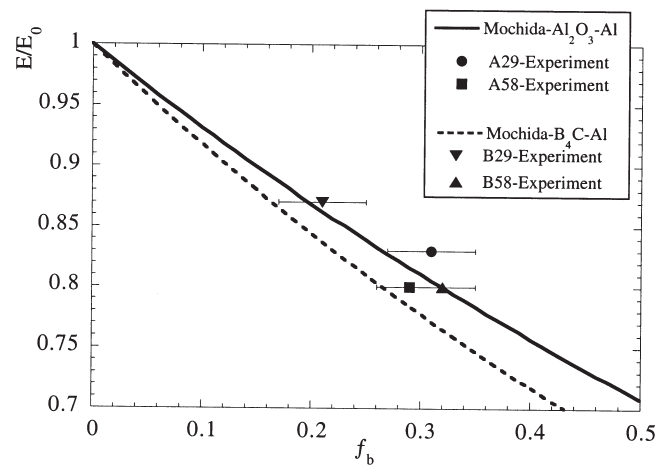

Fig. 7. Comparison of predicted values for $f_{\mathrm{b}}$ through Mochida's model with experimentally determined values. 

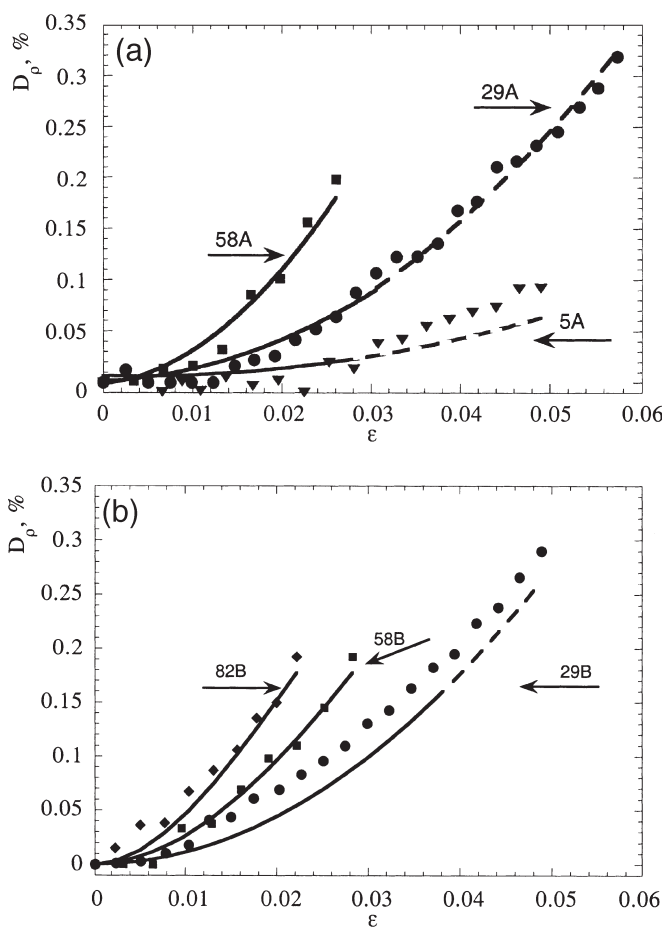

Fig. 8. Correlation of the measured evolution of $D_{\rho}$ (full symbols) with the predicted curves (full and dashed lines) in

(a) $\mathrm{Al}_{2} \mathrm{O}_{3}-\mathrm{Al}$ composites and (b) $\mathrm{B}_{4} \mathrm{C}-\mathrm{Al}$ composites.

large reinforcements in both composite systems; for composites 82B, 58B, 58A and 29A agreement between model and experiment is satisfactory. In composites $29 \mathrm{~B}$ and $5 \mathrm{~A}$ the calculated curves for the evolution of $D_{\rho}$ slightly underestimate the measured data. This can be understood based on the fact that in these composites there is a certain amount of matrix cavitation, which is not related to particle fracture. Qualitatively, one can argue that for the same drop in modulus a larger volume fraction of matrix voids is necessary compared to voids generated by particle cracking. Hence the drop in density as a consequence of both matrix voids and broken particles, for a given drop in Young's modulus, is larger than for the case where all voids are generated by strain induced separation of broken particle segments, as assumed in the present analysis.

In summary, the simultaneous application of several techniques to characterise and measure damage has the advantage of establishing a clear picture of the mechanisms controlling the degradation of a material's properties; in particular, the correlation between the two damage parameters $D_{E}$ and $D_{\rho}$ provides information on the nature of damage within the material. Furthermore, each of these parameters has specific utility: $D_{E}$ is a parameter sensitive to the amount of broken particles, while $D_{\rho}$ is informative on the level of accumulated damage due to matrix plasticity - whether that be cracked-particle opening or matrix voiding.

\section{CONCLUSIONS}

- Damage as measured from the evolution of density and Young's modulus in infiltrated particle reinforced aluminium composites is a strong function of particle size, with larger average sized reinforcements accumulating damage at a higher rate.

- Direct observations of damage micromechanisms corroborate the findings of the indirect measures and indicate that particle fracture is the predominant damage mechanism in the $\mathrm{Al}_{2} \mathrm{O}_{3}-\mathrm{Al}$ composites while two concurrent phenomena contribute to damage accumulation in the $\mathrm{B}_{4} \mathrm{C}-\mathrm{Al}$ composites, namely matrix voiding and particle fracture.

- Damage parameters calculated from the evolution of density and Young's modulus differ by one to two orders of magnitude in these composites. A micromechanical analysis is developed to explain the differences and to link the two damage parameters.

Acknowledgements-The authors gratefully acknowledge funding from the Swiss National Science Foundation, project No. $20-55291.98$

\section{REFERENCES}

1. Bonora, N., Iacoviello, F. and Newaz, G. M., in Eleventh International Conference on Composite Materials, ed. M. L. Scott. Woodhead Publishing Ltd, Gold Coast, Australia, 1997, p. 348.

2. Llorca, J. and Poza, P., Mater. Sci. Eng., 1994, A185, 25.

3. Kennedy, A. R. and Wyatt, S. M., Compos. Sci. Technol., $2000,60,307$.

4. Mummery, P. and Derby, B., Mater. Sci. Eng., 1991, A135, 221-224.

5. Nutt, S. R. and Needleman, A., Scripta Metall. Mater., 1987, 21, 705.

6. Singh, P. M. and Lewandowski, J. J., Metall. Trans., 1993, 24A, 2531.

7. Vaidya, R. U., Song, S. G. and Zurek, A. K., Phil. Mag., 1994, A70, 819.

8. Weng, B. J., Chang, S. T. and Shiau, J. S., Scripta Metall. Mater., 1992, 27, 1127.

9. Whitehouse, A. F. and Clyne, T. W., Acta Metall. Mater., 1993, 41, 1701.

10. Yang, J., Cady, C., Hu, M. S., Zok, F., Mehrabian, R. and Evans, A. G., Acta Metall. Mater., 1990, 38, 2613.

11. Yang, J. Y., Zok, F. W. and Levi, C. G., in Processing, Properties and Applications of Cast Metal Matrix Composites, ed. P. K. Rohatgi. TMS, Warrendale, 1996, p. 77.

12. You, C. P., Thompson, A. W. and Bernstein, I. M., Scripta Metall., 1987, 21, 181.

13. Bourgeois, N., Derrien, K. and Baptiste, D., in The Tenth International Conference on Composite Materials, ed. A. Poursartip and K. Street. Woodhead Publishing Ltd, Whistler, Canada, 1995, p. 241.

14. Corbin, S. F. and Wilkinson, D. S., Acta Metall. Mater., 1994, 42, 1311.

15. Hu, M. S., Scripta Metall. Mater., 1991, 25, 695.

16. Hunt, W. H. Jr., Brockenbrough, J. R. and Magnusen, P. E., Scripta Metall. Mater., 1991, 25, 15.

17. Loyd, D. J., in Intrinsic and Extrinsic Fracture Mechanisms in Inorganic Composite Systems, ed. J. J. Lewandowski and W. Hunt. TMS, Warrendale, USA, 1995, p. 39. 
18. Murphy, A. M. and Clyne, T. W., in The Tenth International Conference on Composite Materials, ed. A. Poursartip and K. Street. Woodhead Publishing Ltd, Whistler, Canada, 1995, p. 35.

19. Nayeb-Hashemi, H. and Shan, D., Mater. Sci. Eng., 1999, A266, 8.

20. Padney, A. B., Majumdar, B. S. and Miracle, D. B., Metall. Mater. Trans., 2000, 31A, 921.

21. Plumtree, A. and Mummery, $\mathrm{P}$, in The Tenth International Conference on Composite Materials, ed. A. Poursartip and K. Street. Woodhead Publishing Ltd, Whistler, Canada, 1995 , p. 257

22. Qin, S., Chen, C., Zhang, G., Wang, W. and Wang, Z., Mater. Sci. and Eng., 1999, A272, 363.

23. Song, S., Gray III, G. T. and Roberts, J. A., Metall. Trans., 1996, 27A, 3739.

24. Whitehouse, A. F. and Clyne, T. W., Composites, 1993, 24, 256.

25. Whitehouse, A. F. and Clyne, T. W., Mater. Sci. Technol., 1994, 10, 468.

26. Bao, G., Acta metall. mater., 1992, 40, 2547.

27. Brockenbrough, J. R. and Zok, F. W., Acta metall. mater., 1995, 43, 11.

28. Finot, M., Shen, Y. L., Needleman, A. and Suresh, S., Metall. Trans., 1994, 25A, 2403.

29. Ghosh, S. and Moorthy, S., Acta mater., 1998, 46, 965.

30. Llorca, J., Martin, A., Ruiz, J. and Elices, M., Metall. Trans., 1993, 24A, 1575.

31. Llorca, J., Needleman, A. and Suresh, S., Acta metall. mater., 1991, 39, 2317.

32. Kiser, M. T., Zok, F. W. and Wilkinson, D. S., Acta mater., 1996, 44, 3465.

33. Poole, W. J. and Dowdle, E. J., Scripta mater., 1998, 39, 1281 .

34. Weber, L., Kouzeli, M., San Marchi, C. and Mortensen, A., Scripta mater., 1999, 41, 549.

35. Lemaitre, J., A Course on Damage Mechanics. SpringerVerlag, Berlin, 1992.

36. Montheillet, F. and Moussy, F. ed. Physique et Mécanique de l'Endommagement, Les Editions de Physique, Les Ulis, 1986.

37. Buffière, J. -Y., Maire, E., Cloetens, P., Lormand, G. and Fougères, R., Acta mater., 1999, 47, 1613.
38. Mummery, P. M. and Derby, B., J. Mater. Sci., 1994, 29, 5615 .

39. Mummery, P. M., Anderson, P., Davis, G. R., Derby, B. and Elliott, K. C., Scripta Metall. Mater., 1993, 29, 1457.

40. Rabiei, A., Kim, B. N., Enoki, M. and Kishi, T., Scripta Mater., 1997, 37, 801.

41. Singh, P. M. and Lewandowski, J. J., in Intrinsic and Extrinsic Fracture Mechanisms in Inorganic Composite Systems, ed. J. J. Lewandowski and W. Hunt. TMS, Warrendale, USA, 1995, p. 57.

42. Vedani, M. and Gariboldi, E., Acta mater., 1996, 44, 3077.

43. Zong, B. Y., Lawrence, C. W. and Derby, B., Scripta Mater., 1997, 37, 1045.

44. Caceres, C. H. and Griffiths, J. R., Acta mater., 1996, 44, 25.

45. Li, M., Ghosh, S. and Richmond, O., Acta mater., 1999, 47, 3515.

46. Simone, A. E. and Gibson, L. J., J. Mater. Sci., 1997, 32, 451 .

47. Mackenzie, J. K., Proc. Roy. Soc. Lond., 1950, B63, 2.

48. Viala, J. C., Bouix, J., Gonzalez, G. and Esnouf, C., J. Mater. Sci., 1997, 32, 4559.

49. Nieh, T. G. and Chellman, D. J., Scripta metall., 1984, 18, 925.

50. Prangnell, P. B., Downes, T., Stobbs, W. M. and Whithers, P. J., Acta metall. mater., 1994, 42, 3437.

51. Ratcliffe, R. T., Brit. J. Appl. Phys., 1965, 16, 1193.

52. Xu, Z. R., Chawla, K. K., Wolfenden, A., Newman, A., Ligget, G. M. and Chawla, N., Mater. Sci. Eng., 1995, A203, 75.

53. Mochida, T., Taya, M. and Obata, M., JSME, 1991, 34, 187.

54. Mummery, P. M., Duradola, J. F., Gallernault, M. and Derby, B., in Intrinsic and Extrinsic Fracture Mechanisms in Inorganic Composite Systems, ed. J. J. Lewandowski and W. Hunt. TMS, Warrendale, USA, 1995, p. 77.

55. Zong, B. Y., Guo, X. H. and Derby, B., Mater. Sci. Technol., 1999, 15, 827.

56. H. E. Boyer and T. L. Gall ed. Metals Handbook, Desk Edition. American Society for Metals, Metals Park, OH, 1985.

57. Shneider, S. J. ed. Ceramics and Glasses. ASM International, Metals Park, OH, 1991. 